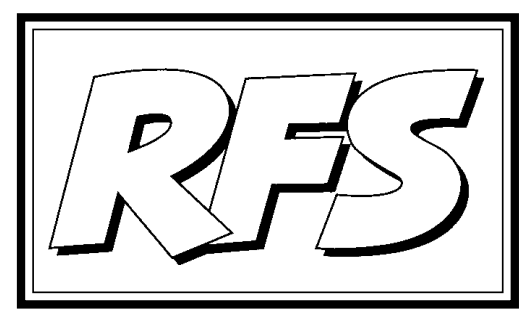

Revista de Fomento Social, 56 (2001), 649-670

\title{
La ley 8/2000, ¿una ley para la integración de los inmigrantes? ${ }^{1}$
}

\section{- Ma del Carmen RODRIGO GAMERO² y J uan Carlos REBOLLO GONZÁLEZ ${ }^{3}$ -}

\section{Introducción}

La inmigración no es uno de los fenómenos sociales más modernos. Desde el hombre deAtapuerca hasta nuestros días nos hemos caracterizad o por ser una especie a la que le gustaba bastante cambiar de lugar donde vivía. Esto no siempre ha supuesto una experiencia gratificante. Los motivos siempre han sido los mismos: el buscar mejores formas de vida, unas mejores condiciones económicas, sociales, de paz, democracia o libertad. Siempre la gran cuestión ha sido la integración en los lugares de acogida.

El concepto integración hace referencia a un proceso, por el que uno va

1 Ley Orgánica 8/ 2000 de 22 de diciembre, de reforma de la Ley Orgánica 4/ 2000, de 11 de enero, sobre Derechos y Libertades de los Extranjeros y su Integración Social, BOE (23 diciembre 2000).

2 Antropóloga Social y Trabajadora Social

3 Abogado de Cáritas Diocesana de Burgos. Profesor de Formación Profesional (Colegio La Merced-J esuitas). Miembro del Centro Ignacio Ellacuría de Burgos. 
adquiriendo apariencia de donde vive o está. Pero hoy en día este sentido de integración es interpretado como la forma de hacerse igual a los demás y por ello de perder lo que uno puede aportar.

La Real Academia ha definido la integración como la acción de integrar o integrarse. En cuanto a lo primero, posteriormente lo define como formar un todo entre las partes; en cuanto a lo segundo, nos desvela una acción que debe realizar el no integrado por meterse en un grupo que está integrado. Según como lo analicemos semánticamente, construiremos un concepto que nos empujará a todos a hacer algo, o bien implicará tan solo las fuerzas del que está fuera y apartado.

Como muy bien establece J. ASENSI ${ }^{4}$, la integración social es muy distinta a la cultural: con tal distinción se quería expresar que, si bien el extranjero se va a ver sometido al ordenamiento jurídico vigente en la sociedad que le acoge $o$ le permite vivir, nada puede impedir el que mantenga las peculiaridades culturales, de lengua, costumbres, creencias, etc. y mucho menos se le imponga un sistema o modelo cultural concreto.

La Ley $4 / 2000^{5}$, en su versión corregida por la Ley $8 / 2000$, no tiene suficientemente en cuenta esta realidad. Lo peor es que confunde ambas formas de integración, y termina por imponer modelos concretos en ciertos ámbitos. No es más que la traslación hecha del modelo cultural vigente en la sociedad que acoge al inmigrante.

La integración de los inmigrantes no se puede basar sólo en la actividad de la administración, ni mucho menos en la conexión con una ley, sino en el entramado legislativo que se ha realizado en torno al tema de la extranjería. En nuestro caso, se parte de la Ley Orgánica para desembocar en los planes del Gobierno, como el GRECO (Programa Global de Regulación y Coordinación de la Extranjería y la Inmigración), o los decretos y reglamentos, que marcarán la verdadera aplicación de la Ley. De ahí que, en último término, es el deseo de un gobierno, y no la voluntad legislativa de la soberanía popular, la que marca por donde va a ir la integración. Esto es paradójico porque la acción final de integrar e integrarse es de la sociedad. Y es aquí donde debemos apostar fuerte, pues nos jugamos la adaptación de unos y otros, para conseguir transformar la sociedad que realiza la recepción. Ello dará

4 J. Asensi y otros (2000), Comentarios a la Ley de Extranjería, Ed. Edijus, p. 27.

5 Ley Orgánica 4/2000 de 11 de enero sobre Derechos y Libertades de los Extranjeros y su Integración Social, BOE (24 enero 2000). 
lugar, por tanto, a un nuevo modelo de sociedad y por tanto significa una oportunidad de evolución. Sin embargo si no aprovechamos nuestra oportunidad, quedaremos anclados al pasado, a través de no afrontar el presente con seriedad y visión de integración ${ }^{6}$.

\section{Un poco de historia en la regulación de la extranjería}

El punto de partida de toda regulación en España es la Constitución. Ello es debido a dos motivos: porque es la norma más importante en la jerarquía del ordenamiento jurídico, y porque su redacción implicó el comienzo de un periodo en España caracterizado por el establecimiento de un sistema democrático, el cual, por muy en crisis que parezca estar, es el modelo político en el que hoy nos movemos.

En la época constitucional era más importante el proceso emigratorio que el inmigratorio. No éramos capaces de pensar en esos momentos que una persona quisiera venir a vivir en nuestro país. En esos momentos todos mirábamos hacia el exterior, donde, según se decía y veíamos, se vivía mucho mejor. Según el Anuario Español de Inmigración, en 1975 había 65.289 extranjeros; en 1980 esa cifra se había multiplicado casi por tres y vivían en España 182.045.

La Constitución estableció en su artículo 13 la referencia a los extranjeros. No fue uno de esos artículos largamente comentados, ni objeto de grandes controversias, como lo fueron otros, sin duda más interesantes para las preocupaciones de aquellos momentos. En dicho art. 13 se reconocen concretamente unas garantías para los derechos de los extranjeros, que entonces se consideraban fundamentales. Se establece algo que luego resultó muy discutido desde las primeras normas sobre inmigración: que los extranjeros contarán en España con las libertades y derechos que se regulan en el Título I, excepto los contenidos en el artículo 23, es decir, los derechos políticos ( posteriormente se matizarían, respecto a la participación política en la administración local, siempre que exista la correspondiente reciprocidad con sus países de origen) ${ }^{7}$.

6 L. J. Del Rio (2001), Globalización e inmigración. El reto del Siglo XXI. (I y II), La Ley no 5334.

7 Sobre este apartado podemos ver: I. LÁZARo (2001), Retos y problemas de la nueva legislación en materia de inmigración, Conferencia impartida en Burgos dentro del Seminario de Inmigración, Centro Ignacio Ellacuria; E. Pérez (1987), Derecho Internacional Privado. Vol. 1, UNED, pp. 217-283. 
Las normas contemporáneas de la Constitución se dirigían preferentementea regular la emigración y a garantizar la conexión con nuestros emigrantes. Fruto de ellas son las casas regionales y otras instituciones similares. Existían además ciertas normas, que regulaban la entrada de extranjeros, las cuales no tenían excesiva importancia en un Estado que quería convertirse en una potencia turística. Una de las primeras normas que se hicieron en torno a la inmigración, en desarrollo de los preceptos constitucionales, fue la Ley de Asilo de 1984. Esta ley amplía el desarrollo que hacía de esta figura el Tratado de Ginebra ${ }^{8}$, del que España es parte.

La primera norma que abordó la extranjería fue la Ley de $1985^{9}$ y posteriormente su reglamento de 1986. A pesar de tratarse de una Ley Orgánica, que por lo tanto necesita de mayorías cualificadas para poder ver la luz, el texto no fue muy debatido: su tono fue restrictivo.

Esta Ley de 1985 obedeció a una exigencia de nuestra futura entrada en la Unión Europea: por tanto hereda la política comunitaria, que claramente diferenciaba a los trabajadores comunitarios de los de terceros países no pertenecientes a la Unión. Es, en realidad, una ley de extranjería, y no de inmigración. Así se deduce del hecho de establecer permisos ordinarios de residencia por cinco años como máximo, lo que indica que no había voluntad política de dotar de estabilidad a la residencia de los extranjeros. Tampoco contemplaba esta Ley la reagrupación familiar que sólo se mencionará en el Reglamento de 1986. Pero éste no se configura como un derecho de los inmigrantes, y tampoco se matiza ni su contenido ni su alcance. Podemos decir que es a partir de este momento cuando empieza para los inmigrantes el desasosiego y el miedo a que su situación no sea regularizada, e incluso empiezan a quebrarse para ellos las expectativas de una vida estable en España.

En 1991 se presenta ante el Parlamento una Proposición no de Ley, que es el primer texto que habla de inmigración. En ella se establece cuál iba a ser la política española en este campo, basándola en tres líneas fundamentales, que eran las que se habían marcado en la Unión Europea. Estas líneas son: control de fronteras, integración de los inmigrantes y cooperación al desarrollo en los países de origen de los inmigrantes.

8 Convención sobre Estatuto de Refugiado (Ginebra, 28 de julio de 1951).

9 Ley Orgánica 7/ 1985 de 1 de julio de los Derechos y Libertades de los Extranjeros. 
En 1994 se vuelve a dar una vuelta de tuerca al reformar la legislación sobre asilo y volver a los postulados y límites del Tratado de Ginebra.

En 1996 se produce un hecho cuando menos curioso, determinado por la situación política del partido mayoritario, el PSOE, en el Parlamento. Como no contaba con la mayoría necesaria para cambiar la Ley de extranjería y ante el peligro de que una nueva ley fuese más restrictiva que la entonces vigente, optó por sacar sólo un nuevo reglamento. Fue grande la participación política y social en todo su proceso de elaboración. En muchos aspectos iba más allá que la propia Ley, lo que permite afirmar que, en cierto modo, era ilegal. Pero como en ciertos aspectos era positivo para los inmigrantes, no se recurrió ante los tribunales.

Después de todas estas vicisitudes llegamos al año 2000, en que nos encontramos con una nueva Ley, nacida como fruto de un enfrentamiento entre el Ministerio de Interior y el de Trabajo, y que cuenta con el respaldo de casi todos los grupos parlamentarios, excepto el partido político que gobierna en esos momentos. Por esta razón, desde el momento mismo en que fue aprobada, el Gobierno anunció que la cambiaría.

Esta reforma legal viene motivada por la comunitarización que se produce con el Tratado de Amsterdam de los temas de J usticia e Interior, lo que exige una homogeneización legislativa en esas materias.

La nueva Ley fue un paso adelante, ya que abordaba la extranjería como un fenómeno estructural ${ }^{10}$. Abandona la línea de una ley control, para convertirse en una ley que apostaba por la integración. Por ello regulaba el permiso permanente de residencia y configuraba el reagrupamiento familiar como un derecho del inmigrante. Además dotaba a los inmigrantes en situación irregular de un bagaje muy amplio de derechos y libertades públicas, y les concedía amplios derechos sociales.

Presentaba, sin embargo, dos problemas básicos. En primer lugar, no era coherente con las líneas básicas del Estado en materia de inmigración, cual era el control de fronteras. El segundo problema es que, si bien dotaba de derechos sociales a los inmigrantes, no hacía una previsión de los recursos sociales necesarios para satisfacerlos, ni el tema tuvo reflejo alguno en la Ley de Presupuestos de ese año.

10 P. Orejudo (2000), “El régimen de extranjería según la Ley Orgánica 4/2000 de 11 de enero, sobre derechos y libertades de los extranjeros en España y su integración social", La Ley no 5080 . 
Paralelamente a esta actividad legislativa interna, España firmó en estos años una serie de tratados tanto multilaterales como bilaterales. Entre los primeros nos encontramos con todos los tratados que tienden a configurar un tratamiento homogéneo de las figuras de asilo y refugio, y con el Tratado de Schengen, que es el que está marcando la política comunitaria en materia de extranjería. En los tratados bilaterales existen dos finalidades distintas: unos buscan la repatriación de los inmigrantes en situación irregular, o que no se les permite la entrada en España; otros fomentan la adquisición de la doble nacionalidad. Estos últimos han sido firmados con países históricamente relacionados con España, y son un intento por parte del gobierno de utilizar la nacionalidad como instrumento de inserción en nuestra sociedad.

\section{Un acercamiento a la actual Ley de extranjería}

La Ley $8 / 2000$, actualmente vigente, se configura a través de una reforma de la anterior Ley Orgánica 4/2000, de la que hereda el nombre. La reforma se justifica, de acuerdo a lo que establece su Exposición de Motivos, por dos motivos diferentes.

El primer motivo es que, desde la entrada en vigor de la Ley $4 / 2000$, se ha producido un cúmulo de cambios en la realidad de la inmigración que hacen necesario una adaptación. La Ley 4/2000, entra en vigor el 1 de febrero. A la vez se aplica un procedimiento extraordinario de regularización, mientras se sigue utilizando el Reglamento de 1996 como instrumento real de aplicación de lo contenido en la Ley. El 22 de diciembre del mismo año 2000 se aprueba la reforma, que se inició previamente, claro está. ¿Tiene, entonces, sentido este primer motivo aducido? La verdad es que no ha dado tiempo a verificar esos cambios; muchas de las cuestiones establecidas en la Ley deben desarrollarse por un Reglamento, y el que se aplica es de 1996. En todo caso, los verdaderos problemas se presentan en la regularización, y no en la aplicación de la Ley ${ }^{11}$.

Posteriormente se ha modificado esta argumentación para decir que la Ley $4 / 2000$ producía un efecto llamada en los inmigrantes. Pero ese efecto llamada es sin duda nuestra forma de vida, y su difusión de forma magnificada a través de los medios de comunicación.

11 Secretaría de Política Social de CC.0O. (septiembre 2000), Informe sobre la reforma de la LO 4/ 2000 sobre derechos y libertades de los extranjeros en España y su integración social. 
Como bien establece X. Etxeberría ${ }^{12}$, nuestra sociedad es hipócrita al admitir y regular la entrada de aquellas personas que huyen de sus países por persecución política y ponerle, en cambio, trabas a los que vienen huyendo de la miseria. ¿No son dos huidas paralelas?, ¿no estamos hablando de la misma causa, un gobierno incapaz de gestionar su país como debe?, ¿por qué a unos les cerramos las puertas y a otros no?

El segundo de los motivos de esta reforma es adaptar la normativa a los compromisos comunitarios asumidos por España (en concreto, aunque no se menciona expresamente, el Acuerdo de Tampere). Lo que se hace, en realidad, es trasladar el Tratado de Schengen a nuestra legislación, pues el Acuerdo de Tampere no son otra cosa que criterios de aplicación del citado tratado. Dichos criterios consagran la diferenciación entre los extranjeros residentes en los países de la Unión Europea, que tienen su situación regularizada y los que carecen de regularización. Esta diferenciación se establece siempre dentro del marco de los derechos humanos, pero se concreta en el principio de la desigualdad, como base del desarrollo y armonización de las políticas de extranjería. En el fondo, el inmigrante vuelve a ser percibido como amenaza para nuestro bienestar y para nuestra identidad.

La legislación española regula de modo diferente a los nacionales de los Estados miembros de la Unión Europea y a los de otros Estados. A éstos últimos se refiere la actual Ley de extranjería.

Esta Ley establece cuatro posibles situaciones de los extranjeros en España, con consecuencias jurídicas diferentes: la residencia, para los que permanecen en España por más de tres meses y cuentan con la autorización administrativa (puede ser residencia temporal o permanente); la estancia, que supone la permanencia en España por menos de noventa días con autorización administrativa; la situación irregular, de los que no tienen autorización administrativa para permanecer en España (porque nunca la tuvieron o porque caducó la que tenía), y la situación irregular pero empadronado en los ayuntamientos. A cada uno de estas situaciones la Ley dota de unos derechos distintos.

La situación en cuanto a los derechos ha variado sustancialmente. En la anterior Ley se establecía una igualdad en su aplicación respecto de los nacionales. Actualmente la igualdad ha pasado a ser un criterio en la

12 X. Etxeberría (2000), Ética de la diferencia, Universidad de Deusto, p. 121. 
interpretación en el uso de esos derechos: ésto conlleva una diferenciación de los nacionales en la práctica, ya que, ante un mismo derecho, un nacional puede tener una serie de prerrogativas, que no se reconocen al extranjero. El punto más debatido al respecto ha sido la desaparición de los derechos fundamentales y libertades públicas para los inmigrantes que no están en situación regularizada. A estos se les ha mantenido algunos derechos sociales mínimos, que en modo alguno garantizan la no marginación de los inmigrantes irregulares.

En este punto la polémica se ha centrado en el Texto Constitucional: ¿permite éste negar los derechos fundamentales a los inmigrantes? En concreto, se trata de los derechos de asociación, reunión, manifestación, huelga y sindicación.

El Delegado del Gobierno para la Inmigración dice que estos derechos son sociales y no fundamentales. Pero en la Constitución aparecen regulados en el Capítulo II del Título I, que hace referencia a los derechos fundamentales y libertades públicas y en ningún momento los califica de sociales. El Defensor del Pueblo, en una decisión muy controvertida, optó por no presentar recurso de inconstitucionalidad, basándose en que el Tribunal Constitucional en 1987 ya se había manifestado en torno a este problema, respecto a la Ley de 1985, dando entonces la razón a su restricción.

Por el contrario, el Informe del Consejo General del Poder J udicial, previo a la aprobación de la Ley ${ }^{13}$, viene a manifestar una opinión contraria a la mantenida por el Gobierno e interpreta de forma distinta la misma Sentencia de 1987 del Tribunal Constitucional. Como el Grupo Parlamentario Socialista ha interpuesto recurso de inconstitucionalidad, después de la negativa de hacerlo por parte del Defensor del Pueblo, el propio Tribunal Constitucional habrá de manifestarse sobre ello.

Pero conviene advertir, ya desde ahora, que la sentencia del Tribunal Constitucional de 1987 sólo es aplicable a la Ley de 1985'14. La Sentencia estableció claramente que cualquier restricción en los derechos fundamentales respecto a los establecidos para los nacionales no era constitucional. $Y$ en cualquier caso hay ciertos derechos, como el derecho de huelga y de

${ }^{13}$ Este informe fue aprobado por todos los miembros del Consejo General del Poder J udicial, excepto los nombrados a propuesta del Partido Popular.

14 Unión Progresista de Fiscales (2001), Algunas consideraciones críticas sobre la reforma de la Ley de Extranjería, Madrid. 
sindicación, que se reconocen como derechos fundamentales de los trabajadores en la Constitución. En cambio, la Ley no los reconoce a los que están en una situación irregular, mientras que sí se reconocen a través de otras construcciones jurídicas: por ejemplo, la Ley reconoce que la relación laboral entre el empresario y el inmigrante que se realiza sin la preceptiva autorización administrativa produce todos sus efectos, por lo que hay que entender que le serán de aplicación estos derechos, que están configurados como inherentes a los trabajadores.

Falta también en la Ley una clara distinción entre la inserción social y cultural, tampoco recogida en la política del Gobierno. En este sentido se garantizan los derechos sin tener en cuenta las peculiaridades culturales de los pueblos. Tales derechos corren el riesgo de quedarse en papel mojado. Por esta razón la propia ONU, cuando se ocupa de derechos humanos, cada vez tiene más en cuenta las distintas culturas que conviven sobre el planeta y que van a ser los receptores de esos derechos.

Sobre cómo poder llevar a cabo la integración social y cultural podemos encontrar dos ejemplos muy diferentes en democracias vecinas ${ }^{15}$. En Estados Unidos se permite que el individuo siga su propia moral o se comporte de acuerdo a una determinada cultura e identidad, siempre que no caiga en radicalismos, no viva de una manera fundamentalista y respete las reglas del juego constitucional ${ }^{16}$. Francia tiene una comprensión de la ciudadanía mucho más política que etnocultural: de hecho se obliga al inmigrante a abandonar ciertas prácticas sociales y adoptar otras, lo que puede conducir a cierto etnocentrismo, así como al abandono de la vía de la integración igualitaria del inmigrante.

En este sentido la Ley española parece atenerse al modelo francés: consecuentemente, va imponiendo una serie de pautas culturales, tales como un modelo familiar, una forma de vida casi en exclusiva dependiendo

15 X. ETXeberría, "El extranjero en la cultura europea de nuestros días", en: El extranjero como igual y como extraño, Universidad de Deusto, pp. 413 y ss.

16 Aunque lo explicado aquí se mantiene como principio inspirador de la política norteamericana de inmigración, después de los atentados terroristas del 11 de septiembre de 2001 las cosas han cambiado: los inmigrantes de origen árabe se han visto coaccionados a no hacer grandes manifestaciones de su religión o cultura, incluso son invitados a ir a las comisarías para explicar dónde estaban en la referida fecha. Sobre este tema podemos ver dos interesantes trabajos: P. Aguelo (2001), Los derechos de los inmigrantes tras el 11 de septiembre, Reicaz (www.extranjería.net); E. SAGARRA (2001), La nueva legalidad en el marco del nuevo orden internacional, Reicaz (www.extranjería.net). 
del trabajo ajeno, etc.; y sobre todo impide la alegación de cuestiones religiosas o culturales para justificar el incumplimiento de derechos fundamentales tal como son concretados a través de la interpretación dada por la legislación española.

Otro de los instrumentos de inserción que, aunque hemos nombrado anteriormente, no lo hemos analizado, es el de la reagrupación familiar ${ }^{17}$. Este derecho se reconoce tan sólo para los inmigrantes que sean residentes en España de forma regular. Podemos hacer una doble lectura.

Referido al inmigrante mismo, este derecho es patrimonio exclusivo suyo, y no de su familia. De este modo, si el inmigrante no lo ejerce, el resto de la familia se ve privado de él e incluso en situación de desamparo; además su duración viene ligada al del permiso de residencia del inmigrante titular del derecho. Ahora bien, este derecho a vivir en familia y a una vida privada en familia es, sin duda, un derecho fundamental, y no social, de toda persona humana: por consiguiente, no se puede limitar a quien esté en una determinada situación legal.

Si se entiende como derecho referido al núcleo matrimonial y a los hijos menores de edad, se está imponiendo un modelo familiar concreto y excluyendo otros tipos o modelos de familia, aunque sean dentro de este núcleo, como es el caso de las parejas de hecho o las parejas formadas por homosexuales. Se configura entonces casi como un derecho a la vida conyugal, y no a la vida familiar. Pero, en las culturas de origen de los inmigrantes, existen otras muchas formas de organización familiar aparte del matrimonio. Por otra parte, se ha perdido la posibilidad de reagrupar a otros familiares, distintos del cónyuge y los descendientes, por razones humanitarias: en la práctica se podrían seguir de aquí muchos problemas, sobre todo si estos conceptos se aplican estrictamente, por la mucha inseguridad que crean al no existir una interpretación uniforme, ni en el derecho ni, sobre todo, por parte de la Administración.

Otra de las cuestiones polémicas de la presente Ley son las garantías jurídicas, que se han visto restringidas claramente tras la reforma. La primera de estas garantías es el derecho y la obligación a estar documentado, incluida, claro está, la documentación que demuestra su situación en

17 Sobre este tema cf. R. M. MoLIneR (2001), "Reagrupación familiar y modelo de familia en la LO 8/2000 de Derechos y Libertades de los Extranjeros en España", La Ley; M. MoYA (2000), "El derecho a la reagrupación familiar en la Ley de Extranjería", La Ley. 
España: por supuesto, se acompaña de la prohibición de ser privados de su documentación.

Otra de las garantías que se ha visto en cierto modo restringida ha sido la de la asistencia jurídica gratuita. Admitida de forma general para los extranjeros en cuanto a su situación administrativa de entrada o permanencia en España, sólo se garantiza a los residentes en situación regular si quieren emprender otro tipo de pleitos, penales, civiles, o laborales, a excepción del campo penal donde se impone la obligación, cuando se es acusado, de comparecer con abogado. Esta privación de la justicia gratuita aumenta la desprotección del inmigrante irregular, sobre todo porque no puede comenzar pleitos para poder exigir sus derechos laborales o civiles o intentar cambiar su situación familiar a través de la separación y el divorcio, etc.

Hay una serie de preceptos en la Ley que van encaminados a agilizar el procedimiento administrativo sobre su situación en España, y que conducen a una desprotección de los inmigrantes. Entre ellos se cuenta la no motivación de las denegaciones de visado, salvo las de reagrupamiento familiar o de trabajo por cuenta ajena, o la inmediata ejecución de los actos dictados en materia de extranjería sin posibilidad de suspensión de los mismos para que se recurran ante los Tribunales. Aunque esto nos pueda parecer una nimiedad cuando se trata de una multa de tráfico, no lo es cuando se trata de la vida de las personas, las cuales han venido hasta aquí para poder sobrevivir. Un ejemplo palpable de ello, que se ve todo los días, es que, antes de permitirles entregar la documentación en la administración, se la revisan y no se la dejan presentar si no está en regla: contrasta tal solución con las normas de procedimiento administrativo, que permiten presentar la solicitud y abrir un plazo de diez días para subsanar aquello que falte. Es en estos hechos donde, en muchas ocasiones, se decide la situación del inmigrante, incluso respecto a su expulsión: porque puede ser expulsado aquél a quien no le hayan admitido la documentación, pero no el que esté en un proceso de regularización (es decir, el que haya podido presentar los papeles en un simple registro de la Administración) ${ }^{18}$.

La regulación del permiso de trabajo se hace desde dos premisas, que son también restrictivas para los inmigrantes, sobre todo para aquellos que ya están instalados en España en situación irregular. Por una parte, se establece

18 Sobre este tema es muy interesante: F. OLIVÁN (2001), "La tutela efectiva y la posible erosión de las garantías constitucionales de los derechos de los extranjeros en el marco de la Ley 8/ 2000", El Foro Manchego, abril. 
un contingente de extranjeros que pueden venir a trabajar, donde no se computan los que vengan por reagrupamiento familiar o los que deban renovar sus permisos. Para poder fijar el contingente se debe contar con que exista necesidad de mano de obra extranjera. De esta manera no es obligatorio establecerlo todos los años. Con ello se pretende limitar de forma clara la cantidad de inmigrantes que puedan venir a trabajar.

La otra premisa es que, antes de otorgar un permiso de trabajo, se ha de contar con un informe del INEM que establezca que en la situación nacional, no sólo de la localidad, no hay mano de obra desempleada para esa profesión. Si el informedice que existe esa mano de obra, no sepodrá otorgar el permiso, salvo en el caso de que se demuestre que no son contratables aquellas personas nacionales que están inscritos como desempleados en el registro del INEM o en el correspondiente de las Comunidades Autónomas con las competencias transferidas.

A estas dificultades debemos unir el que a los inmigrantes en situación irregular sólo les cabe acceder a una situación regular de residencia si demuestran encontrarse en una situación que, bien por motivos humanitarios o por contar con arraigo en el país, así lo aconseje. De todas formas dice la Ley que debe ser el reglamento el que especifique estas posibilidades que ella sólo menciona de forma muy general pero que, en principio, parecen interesantes.

\section{La aplicación de la Ley y el desarrollo reglamentario posterior}

Como ya hemos indicado antes, todo se va a decidir, no en el texto de la Ley, sino en su aplicación práctica, concretamente en su desarrollo reglamentario. Pues bien, desde que entró en vigor la Ley, se han conocido varias versiones del futuro Reglamento que la debe desarrollar. En marzo de 2001 vio la luz el segundo borrador de Reglamento, que ha sido la base sobre la cual se ha elaborado el que finalmente se ha puesto en vigor. El segundo borrador continúa la línea restrictiva de la Ley, preocupándose sobre todo por ofrecer una visión policial y de control de la inmigración, que reduce a la ilegalidad al inmigrante que no tiene una situación regularizada.

Se centraba sobre to do en regular pormenorizadamente los procedimientos de concesión de visad os y permisos, tanto de residencia como de trabajo. En descargo del mismo se ha de decir que el Gobierno lo presentó como un borrador que se sometía a un debate político y social. Después de este borrador hemos conocido otra versión, prácticamente igual, y por fin el 
Reglamento actualmente en vigor ${ }^{19}$. Las diferencias realmente son mínimas, pues no se han recogido más que ciertas matizaciones al mismo, que se presentaron en su día, tanto por partidos políticos como por entidades sociales y ONG que trabajan en el tema de la inmigración.

Todas las propuestas de modificación realizadas tanto por Izquierda Unida como por el PSOE, se reducían a dos puntos, que en verdad son claves, y que han sido tratados deforma un tanto restrictiva por el Reglamento. Estos puntos, que coinciden con aquellos que la Ley trataba de forma más restrictiva, el Reglamento no ha hecho más que endurecerlos más.

El primero de ellos, es el procedimiento para pedir el reagrupamiento familiar: a pesar de tratarse de uno de los instrumentos de inserción más básicos, se le imponen condiciones mayores. Dichas condiciones eran en la Ley: poseer un año de residencia regularizada en España y permiso al menos para otro; además los familiares, durante los dos primeros años de convivencia en este país, quedaban sometidos a la situación del inmigrante titular del derecho al reagrupamiento ${ }^{20}$. Por su parte, el Reglamento exige un informe del ayuntamiento (o, si éste no puedehacerlo, un acta notarial que demuestre que se tiene una vivienda para acoger a esos familiares) y la presentación de nóminas o recibos de cotización a la Seguridad Social (para mostrar que se puede mantener a la familia a reagrupar). Si no se cumplen los requisitos, los familiares a reagrupar se deben quedar en su país de origen. Al no establecerse unos criterios claros en el propio Reglamento, la decisión puede quedar en manos de la Administración, dando lugar a una situación de discriminación al no exigirse requisitos homogéneos.

Pero todavía es mayor la restricción respecto de los familiares reagrupados en su opción legítima a trabajar y así colaborar al sostenimiento económico de la familia: seles impideacceder a un permiso de trabajo hasta que no hayan obtenido la renovación de su permiso de residencia por reagrupación ${ }^{21}$.

19 El Reglamento fue publicado el 21 de julio de 2001 (Real Decreto 864/2001 de 20 de julio) y entró en vigor el 1 de agosto de 2001.

20 La Ley exige de este tiempo para poder solicitar un permiso individual y en el Reglamento se exige este tiempo para que el cónyuge reagrupado pueda obtener permiso de residencia en España si se separa o divorcia.

21 Ya que hasta ese momento es necesario el que se vea la situación nacional de empleo antes de otorgar la autorización, lo que en la práctica impide la concesión de la misma. 
El segundo de los puntos, que establecen tanto IU como el PSOE, en los que se originan estas propuestas de modificación es en la regulación del permiso de trabajo, en dos vertientes, en primer lugar por no aceptarse un permiso de trabajo permanente, y por verse el inmigrante controlado ante cualquier cambio de puesto de trabajo, pues el permiso que tiene mayor duración es de dos años, y con ello se crea una sensación de inestabilidad que influye de una manera muy importante. Aunque la propia Ley, y esta modificación se vería así recogida, establecela excepción de obtención de permiso de trabajo a los inmigrantes que gocen del permiso de residencia permanente que se obtiene después de cinco años de residencia ininterrumpida, y que no se ha querido recoger en el nuevo Reglamento.

Otro aspecto que se ha regulado en el Reglamento es el de la forma de realizar el informe sobre la situación nacional de empleo en el sector que ha solicitado el inmigrante. En esta ocasión seexigen mayores requisitos, ya que hay que tener en cuenta a todos los trabajadores, incluso los Ilamados trabajadores fronterizos capacitados para ejercer la profesión. En el art. 70.1-1.1-c, del Reglamento, se establece, sin entrar a tocar el tema del contingente, que se tendrá en cuenta el hecho de que el empleador no haya podido cubrir su oferta laboral. Esta oferta deberá ser gestionada a través de los servicios públicos correspondientes. Tanta burocracia tiene como resultado que al empresario sólo le interesa en la práctica contratar trabajadores extranjeros, siempre que tengan residencia permanente o que él no encuentre trabajadores nacionales. Otra consecuencia de esto es que diversas ONG y entidades sociales se convierten en autenticas gestorías de estos complicados trámites 22 .

Llama la atención también el artículo 74.1, que establece, como motivo de denegación del permiso de trabajo, el hecho de que la oferta de trabajo tenga unas condiciones inferiores a las marcadas en las normas laborales. Resulta así que el que sufre las consecuencias del abuso del empleador es el trabajador. La solución sería sencilla si se aplicase lo que es válido para el caso de trabajadores nacionales: que las condiciones contractuales que no alcancen las marcadas en las normas laborales se tienen por no puestas. Pero es más fácil optar por no dejar venir al inmigrante...

Al regular la no admisión a trámite de la solicitud del permiso de trabajo

22 A. PAvón (2001), Reagrupación familiar, vivienda, salud y condiciones laborales, Colegio de Abogados de Zaragoza, Servicio de Inmigración. 
en determinadas situaciones, el Reglamento ${ }^{23}$ agrava aún más la situación: porque las enumeran con tal amplitud que lesionan gravemente las garantías jurídicas del inmigrante. En la Ley, cuando le denegaba el permiso de trabajo por cuenta ajena, la resolución se debía motivar; en el Reglamento, basta con mencionar una de las situaciones, sin más alegación.

Algunas de esas causas están determinadas por el Derecho Administrativo, como por ejemplo el hecho de presentar la solicitud ante un órgano incompetente. En este caso las normas ${ }^{24}$ ya han previsto que el órgano incompetente pase la solicitud al que es competente. Otra causa es la de ser "manifiestamente carente de fundamento", una expresión que está falta de una elemental concreción. También llama la atención el que las resoluciones no comunicadas en el plazo de tres meses se han de entender desestimadas: con ello se elude una de las mayores garantías para el administrado, que es el derecho a obtener respuesta a su petición y que ésta sea motivada.

El Reglamento ha venido a consagrar la expulsión como la forma de sanción normal ante cualquier infracción a la Ley y al Reglamento ${ }^{25}$. Con ello se invierte lo establecido en la Ley, que fijó la multa como la sanción normal, dejando la expulsión para algunos casos. Esta circunstancia, unida a la ejecución inminente de las sanciones, sin que se suspenda su aplicación por esperar a la resolución de recursos al menos administrativos (no ya judiciales), genera un perjuicio de difícil reparación, ya que primero se les expulsa y luego se resuelve el recurso. Es lo que ocurrió con los primeros inmigrantes nigerianos que fueron expulsados: cuando estaban ya en su país, un juez decidió suspender la expulsión.

Por otro lado, cuando el art. 118 regula el procedimiento para adoptar la resolución de expulsión, se establece para la misma un margen amplísimo de tres a diez años; y se añade que la expulsión no sólo se refiere al territorio español, sino también a los Estados con los que haya convenio en este sentido, lo que va mucho más allá de la propia Ley. Al establecer la expulsión

23 A. Álvarez (2001), "Algunas irregularidades detectadas en el Real Decreto 864/2001", Entreculturas nำ 41, Cáritas Española.

24 En concreto: el art. 20 de la Ley 30/1992, que regula el procedimiento administrativo, y el art. 2 del Real Decreto 77/1999, que establece la posibilidad de presentar solicitudes en las Comunidades Autónomas y Ayuntamientos con los que haya algún convenio.

25 Sobre este tema son muy interesantes: L. J. DEL Rio (2001), "Detención e internamiento de extranjeros: estatuto jurídico", La Ley no 5.422 y 5.423; A.Asúa (2001), “Política criminal y política de extranjería", Actualidad Penal no 42. 
de terceros Estados, que no tienen parte en el proceso, se les cierran las puertas no sólo para volver a España, sino también a otros Estados. Estos Estados son en concreto los que pertenecen al espacio definido en el Tratado de Schengen: se consigue por esta vía que se refuercen las fronteras de todos ellos.

Un tercer punto, en que se centraban las dos propuestas de modificaciones presentadas por los partidos políticos, era el establecimiento de un sistema permanente de regularización de los inmigrantes que vengan a nuestro país. A la vista de los datos de los Estados receptores de inmigrantes, como Estados Unidos o Francia, las regularizaciones extraordinarias que se repiten periódicamente (y cada vez con más frecuencia, a pesar de que su legislación es mucho más restrictiva que la nuestra) no llegan a lograr el objetivo de ralentizar los flujos de inmigrantes. Un sistema permanente de regularización impediría la existencia de una gran cantidad de personas destinadas en principio a la explotación y a la marginación, precisamente por no poder regularizar su situación.

En estos momentos en España hay unos trescientos mil inmigrantes sin tener una situación regularizada, que se encuentran en ocasiones en situación desesperante al no poder acceder al mercado laboral y obtener así ingresos con los que vivir. Fruto de ello ha sido la gran cantidad de manifestaciones, encierros y demás conflictos generados por estos inmigrantes en situación irregular. Por otro lado existen ciertos colectivos que se mueven mucho mejor en la irregularidad, y que generan con ello mayores beneficios y ventajas, como puede ser el personal del servicio doméstico, etc. Todo esto al final produce un cierta criminalización, consecuencia de la alarma que generan los delitos cometidos por inmigrantes, mucho más fáciles de identificar por las víctimas o en los medios de comunicación.

En el ámbito de la integración, el Reglamento hace una regulación de las Oficinas de Extranjeros y los Centros de Internamiento de Extranjeros, a los que se trata como si fuesen centros penitenciarios. Pero la figura central son los Centros de Migraciones, a través de los cuales desde los poderes públicos se asumirían las funciones que realizan actualmente las ONG y otras entidades sociales, a las que no se les reconoce ya que puedan asumir esa misión, para evitar que se yuxtapongan estructuras de atención social. 


\section{El programa GRECO y la normativa que lo acompaña}

Este Programa del Gobierno español para el periodo comprendido entre 2001 y 2004 ha sido publicado en el BOE el pasado 27 de abril de 2001 con la categoría de Resolución ${ }^{26}$. Se trata de un programa político que desarrolla las tres líneas que se marcaron ya en la Proposición no de Ley del año 1991. No se da la misma importancia a todas ellas de forma que se dedican más medidas al control de los flujos migratorios y por ende de las fronteras que a la integración o a la cooperación para el desarrollo. El programa es, por su alcance temporal, un instrumento que marca la política en materia de inmigración para esta legislatura.

Entre sus objetivos está la integración de los inmigrantes, estableciendo expresamente que los inmigrantes que queremos son los que contribuyan al crecimiento de España. Con ello se impone una visión utilitarista del problema de la inmigración. Se promueven además medidas que fomentan el ejercicio pleno de los derechos, la atención a los inmigrantes en situación de vulnerabilidad y la lucha contra el racismo. Para la regulación de los flujos se arbitran sobre todo medidas de control y policía como son el refuerzo de la seguridad de las fronteras, la lucha contra las redes que propician la inmigración ilegal, el control de ésta y la protección de los menores inmigrantes. Por último se establecen medidas que contribuyan al mantenimiento y refuerzo del sistema de acogida y protección para asilados y refugiados.

El 4 de abril de 2001 se publicaron tres Reales Decretos, que vienen a reforzar el programa GRECO. Son fruto de la legislación anteriormente vigente y tienen una marcada preocupación por la integración de los inmigrantes. Su objetivo es regular, adaptar y transformar tres organismos: el Consejo Superior de Política de Inmigración, el Observatorio Permanente de la Inmigración y el Foro para la Integración Social del Inmigrante.

El primero de ellos es un órgano creado para la cooperación y coordinación entre el Estado, las Comunidades Autónomas y las Administraciones Locales, en materia de inmigración. Su función principal es la de realizar un informe previo a la hora de que el Gobierno fije el contingente anual de inmigrantes trabajadores. Nada se dicesobre la necesidad de contar para ello

26 Es la Resolución de 17 de abril de 2001, de la Delegación del Gobierno para la Extranjería y la Inmigración, por la que se dispone la publicación del Acuerdo del Consejo de Ministros del 30 de marzo de 2001, por el que se aprueba el Programa Global de Regulación y Coordinación de la Extranjería y la Inmigración. 
con la colaboración de ONG o entidades sociales dedicadas a este problema.

El segundo de esos órganos tiene como misión la recogida, análisis y estudio de la realidad, en cuanto a la inmigración se refiere, y se abre a la participación social a través de expertos en esta materia.

El último de los entes ahora reformados es el más participativo. Se trata de un órgano de consulta, cuya función principal ha sido el informar y asesorar sobre cuestiones relativas a la inmigración. Cuenta con la participación de ONG, designadas por el Gobierno a través de un sistema de elección, cuando menos raro, ya que se parece a un concurso para acceder a esas plazas. En el nombramiento de los vocales, pertenecientes a ONG, no se han cubierto los deseos de todos. Por eso varias de las entidades que se han visto excluidas han planteado el poder convocar un punto de encuentro diferente al Foro. Se le impone la obligación de reunirse dos veces al año, pero no se establece con qué finalidad.

\section{Movimientos políticos posteriores a la Ley}

La inmigración se ha convertido en un problema de primer orden en el Estado ${ }^{27}$. Prueba de ello son los artículos casi diarios de la prensa o las noticias de radio o televisión sobre temas relacionados con la inmigración. Por ello ha habido una gran actividad, tanto del Gobierno como de los partidos políticos de la oposición y de entidades sociales y ONG. Se ha creado así un cierto ambiente de preocupación en la sociedad en torno al tema.

Una vez aprobadas estas normas, así como el Reglamento que regula el estatuto del apátrida, y puesto en marcha el Programa GRECO, el Gobierno ha empezado una actividad casi diplomática, empeñándose en firmar acuerdos con los principales Estados de origen de nuestra inmigración. Lo ha hecho con una doble orientación: por un lado, para regular los flujos migratorios y, por otro, para lograr el retorno de personas en situación irregular. El más famoso de estos tratados ha sido el Acuerdo con Ecuador, por el que se promovió la vuelta de miles de inmigrantes originarios de aquel país sin una motivación clara. Este acuerdo reconoce un trato de reciprocidad en cuanto a permisos de trabajo: pero su eficacia práctica es muy

27 Son interesantes al respecto las conclusiones del XI Encuentro de Abogados sobre el Derecho de Extranjería, organizadas por la Subcomisión de Extranjería del Consejo General de la Abogacía Española. 
dudosa, ya que la Ley no reconoce ningún beneficio para este tipo de tratados $^{28}$.

Los partidos políticos con representación parlamentaria han fijado su atención en cuanto a la formulación de propuestas legislativas en dos ámbitos. Por un lado, PSOE (20 de febrero de 2001) y Partido Popular (12 de marzo de 2001) presentaron sendas propuestas de modificación del Código Civil en materia de nacionalidad, con diferencias en cuanto al periodo de tiempo de residencia necesario para solicitar la nacionalidad ${ }^{29}$. Por otra parte, el PSOE, que ha actuado en el tema de la inmigración como abanderado de las posiciones sociales (tanto de ONG como de entidades ciudadanas) más avanzadas en esta materia, presentó el 23 de marzo de 2001 una Proposición de Ley de reforma de la Ley Orgánica 8/2000, que en grandes líneas vuelve a la redacción de la Ley originaria ${ }^{30}$. Pero la actividad más importante ha sido la presentación del Recurso de Inconstitucionalidad contra ciertos artículos de la Ley de extranjería actual ${ }^{31}$. La decisión se tomó ante la negativa, muy criticada por muchos sectores de la política y del mundo social, a hacerlo por el Defensor del Pueblo. En fechas recientes han sido admitidos por parte del Tribunal Constitucional.

Desde que entró en vigor la actual Ley de Extranjería, tampoco los inmigrantes se han quedado parados, ni las entidades sociales que los apoyan. A través de concentraciones y encierros de inmigrantes, en casi todo el Estado, se ha puesto de manifiesto que la aplicación de la Ley no era homogénea en todas las provincias. Esto ha empujado al Ejecutivo, en un esfuerzo por resolver el problema, a firmar acuerdos con los inmigrantes. Con el fin de dotarles de una situación regular, se ha optado por revisar los expedientes que fueron denegados en los diversos procesos de regularización, que han tenido lugar durante la aplicación transitoria de la Ley. Esta revisión se concretó en interpretar ciertos conceptos de forma abierta, detal

28 Recientemente el Delegado del Gobierno para la Inmigración ha manifestado que, dada la situación del mercado laboral en España, no es posible seguir firmando este tipo de acuerdos que regulan los flujos migratorios; es más, que se pone en duda el mantenimiento de los actualmente firmados.

${ }^{29}$ Ambas proposiciones se pueden consultar en el Boletín Oficial de las Cortes Generales de 9 de marzo y de 16 de marzo de 2001.

30 Esta proposición se puede consultar en el Boletín Oficial de las Cortes Generales de 6 de abril de 2001.

31 También se ha presentado por los Gobiernos de varias Comunidades Autónomas. 
manera que lograsen así alcanzar una situación regular de momento. Dos han sido los acuerdos más importantes: el de Barcelona de 8 de febrero de 2001 y el de Valencia de 25 de abril de 2001.

A raíz del cambio en el titular del Ministerio del Interior, se ha visto cómo se arbitraban soluciones con el fin de poder regularizar al máximo número posible deinmigrantes. La fórmula ha sido una relectura del art. 31.4 dela Ley, en el tema del arraigo. Así los escritos de 11 de junio del Foro de Inmigración y del 16 de junio del Delegado del Gobierno para la Inmigración han establecido con claridad, hasta la entrada en vigor el pasado 1 de agosto del Reglamento, qué se debe entender por arraigo.

En este primer año en que, de acuerdo a la nueva Ley, había que fijar un cupo de inmigrantes, hemos visto cómo las ofertas de trabajo para extranjeros se han reducido de tal manera que el Ministerio del Interior, para salvar el cupo, ha tenido que recurrir a los acuerdos que tenía suscritos con los diversos países de origen de los inmigrantes. Los sindicatos y varias ONG han pedido que este año no se estableciese un cupo, y que esas ofertas fuesen cubiertas por los inmigrantes que están ya en España en situación irregular. Al final se ha establecido el cupo en 32.079 inmigrantes ${ }^{32}$, pero los que estén ya aquí de forma irregular deberán volver a sus países de origen.

La resolución que ha aprobado el cupo para el presente año 2002, ha llevado aparejado la prohibición de admitir solicitudes de permisos de trabajo y residencia que se presenten en España, y sólo admite como procedimiento válido el realizado a través del cupo y en sus países de origen. Además se va a regular la posibilidad de que los inmigrantes que quieran un puesto de trabajo en el servicio doméstico puedan residir en España por tres meses y, si en ese periodo de tiempo no encuentran trabajo, deberán regresar a su país. Estas medidas y otras que se acompañan van a producir la marginación total de los inmigrantes que estén o queden en situación irregular ${ }^{33}$.

32 El cupo de inmigrantes se divide en 10.884 para puestos estables y 21.195 puestos temporales. Además se va a regular la posibilidad de que los inmigrantes que quieran un puesto de trabajo en el servicio doméstico puedan residir en España por tres meses y, si en ese periodo de tiempo no encuentran trabajo, deberán regresar a su país.

33 Sobre esta materia ver: E.J. Gómez (Cáritas Española), Algunas reflexiones en torno al Contingente 2002, Reicaz (www.extranjeria.es). 


\section{Conclusiones}

La Ley que hemos estudiado es un instrumento que intenta cerrar las fronteras y regularizar la entrada de todos los extranjeros; no ofrece, en cambio, soluciones serias para el problema dela integración social y cultural de los inmigrantes. Desde 1991 el principio inspirador de la política en materia deinmigración es el cierre de fronteras: es lógico que la Ley responda a ello. El problema se está planteando en estos momentos en lo cotidiano: en las relaciones de trabajo, en el mundo de la escuela, en las relaciones de vecindad.

Llama la atención la visión utilitarista y economicista que se ha dado a las personas extranjeras, tanto en las normas como en los programas del Gobierno. Esta imagen ha sido acogida en los medios de comunicación y está arraigando en la población. Porque ¿es admisible que el Gobierno nos hable de que se necesita un número determinado de personas extranjeras para hacer frente a un problema económico del país?

Todo este conjunto de medidas del Gobierno no han solucionado el problema. Los inmigrantes siguen presionando, con el apoyo de ONG y de las entidades sociales, a una solución para los inmigrantes que estaban ya aquí y para los que siguen viniendo cada día. De momento el Gobierno se niega a abrir un proceso de regularización permanente. Como no seamos capaces de acabar con el flujo de inmigrantes y dado que éstos no pueden ser devueltos en muchas ocasiones a sus países de origen, lo que se está generando de hecho es una bolsa de personas condenadas a la marginación: gente a la que se les fuerza a vivir en una situación lamentable, poniéndolas en manos de empresarios sin escrúpulos y de bandas de delincuentes perfectamente organizadas.

La Administración está resolviendo las solicitudes muy lentamente, lo que no ayuda a acabar con el problema. Tampoco se ha empezado a atender la integración de los inmigrantes: reflejo de ello son las noticias de corte racista que aparecen de vez en cuando en los informativos. La inserción es prioritaria, pues es el paso previo a poder acoger más inmigrantes. Tampoco se atiende debidamente la cooperación con los países que envían inmigrantes. La política de inmigración en este país se sigue basando exclusivamente sobre un sistema de cierre de fronteras y de control del flujo de inmigrantes. Con estos ingredientes va a ser muy difícil llegar a una solución global del problema de la inmigración. Desde luego, no seremos capaces de anticiparnos al futuro de nuestra convivencia. 
La situación de cierta inseguridad en nuestras calles y la costumbre de achacar esta inseguridad a un perfil concreto de personas hace que en estos momentos se culpe de la delincuencia a los extranjeros. Es cierto que desde el resurgir de la inmigración hay delincuentes que son extranjeros, pero no para poder decir que todo inmigrante es un delincuente. Además las operaciones policiales, como la Ludeco o las que siguieron a los atentados del 11 de septiembre, han contribuido a agravar la situación. Esto lleva a mirar con cierta prevención al extranjero, caso que se traslada a todas sus manifestaciones culturales.

Por otro lado, es necesario abordar sin más demora la integración social y cultural de los inmigrantes. Para ello bastará a veces con simples acciones, como el establecer en convenios colectivos de trabajo la posibilidad de cambios de horarios o fiestas laborales, acomodando el trabajo a la cultura propia de los extranjeros (el Ramadán para los musulmanes, la festividad de los santos para los hispanoamericanos, etc.). En esta misma línea sería oportuno prever, en los planteamientos urbanísticos de las ciudades, espacios de referencia cultural de los extranjeros, como puede ser solares para hacer mezquitas, zonas en los cementerios para musulmanes, etc. Estas medidas ya se tienen en cuenta en al gunas ciudades, pero no son todavía al go generalizado y normal en todas las ciudades receptoras de inmigrantes. 